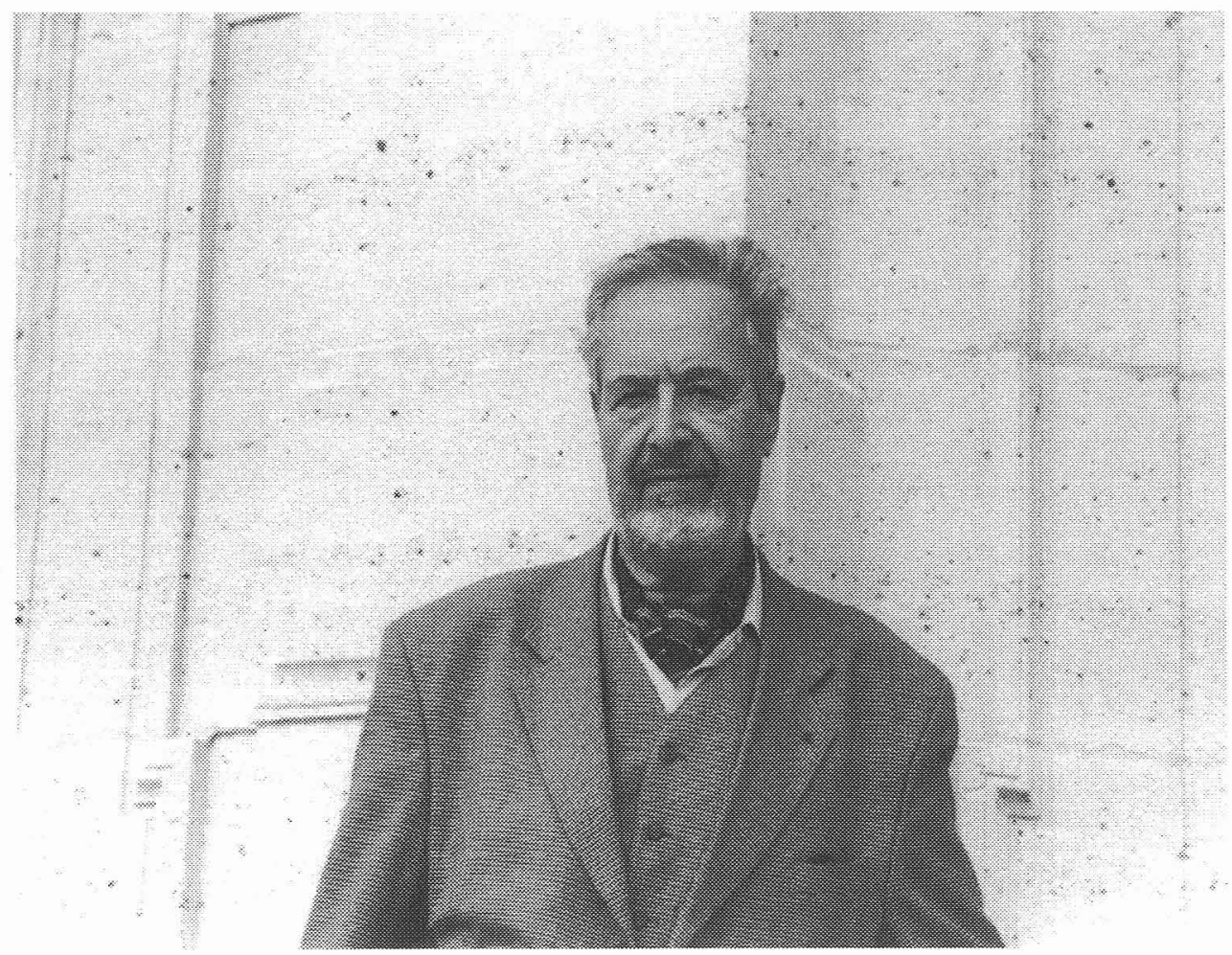

Albert Memmi 


\begin{abstract}
Albert Memmi, a poursuivi une double carrière de chercheur et d'écrivain. Memmi, profondément enraciné dans son terroir natal, est qualifié de "plus grand écrivain tunisien d'expression française" (diction. Bordas des littérat.). L'oeuvre d'Albert Memmi, traduite dans une vingtaine de pays, a obtenu de nombreuses distinctions. Une soixantaine d'ouvrages, de travaux universitaires lui sont déjà consacrés à travers le monde. Oeuvres principales: Romans: La Statue de sel . Préface d'Albert Camus, Corréa, 1953/Gallimard, 1963. Le Scorpion. Gallimard, 1969. Le Pharaon. Julliard, 1988. Poésies: Le Mirliton du ciel. Edit. Lahabé, 1985/Julliard, 1989. Essais et portraits: Portrait du colonisé, précédé du Portrait du colonisateur, préface de Jean-Paul Sartre, Corréa, 1957/ J.J.Pauvert 1966/ Gallimard 1986. L'Homme dominé (le colonisé, le noir, le juif, la femme, le domestique). Gallimard, 1968. Le Racisme. Gallimard, 1982. Ce que je crois. Grasset, 1985. Divers ouvrages: Anthologie des littératures maghrébines. Présence africaine: T I et II, 19641969. Ecrivains francophones du Maghreb. Laffont, 1985. Le Roman maghrébin de langue française. Nathan, 1987.
\end{abstract}

\title{
\&
}

\section{Le Foulon et le mausolée}

L 'un de nos plus anciens rois avait un ami qu'il chérissait entre tous; il lui était un nuit qu'ils avaient bu ensemble, le souverain, perdant l'usage de sa raison, tira sa bague et frappa son ami qui en mourut.

Le lendemain, au sortir du lourd sommeil qui suit l'orgie, il découvrit l'horrible conséquence de son égarement. Le palais retentit de ses lamentations, et longtemps, rien ne put calmer sa douleur. Jusqu'au jour où l'excès de son remords lui inspira une idée aussi funeste que celle que lui avait inspiré l'excès de boisson. Il fit édifier un mausolée où furent ensevelis les restes de sa victime, puis il édicta que quiconque passerait devant le funèbre monument sans se prosterner serait appréhendé et mis à mort. Toutefois, comme il n'était pas d'un fond si mauvais, il concéda que le malheureux pourrait formuler un voeu qui serait toujours exaucé,

La fierté de notre peuple, à l'époque à peine sorti de ses tentes, fut gravement heurtée par cette loi. On raconte qu'une espèce de jeu s'instaura parmi les jeunes hommes, dont on sait la provoquante témérité: c'était à qui, lancé sur un cheval au galop, narguerait les gardes. Hélas plusieurs d'entre eux, rattrapés, y laissèrent la vie; car le défilé au palais des parents et des proches suppliants ne venait jamais à bout de la résolution du roi.

Un vieux foulon, qui avait ainsi perdu un fils se jura de mettre fin à cette iniquité. Muni de son maillet et d'un ballot de laine, il entreprit de traverser, sans se prosterner, la sinistre place. Appréhendé, il fut aussitôt conduit devant le souverain: 

défunt!

—Ainsi, lui dit ce dernier, tu as refusé de rendre hommage à la mémoire de mon ami

-Révérence gardée, Seigneur, ce n'est pas la vérité, répondit le foulon; le dos rendu rigide par l'âge, et chargé comme je l'étais, il m'était impossible de me courber. Et pour vous prouver que je suis respectueux de la loi, j'en réclame au contraire la stricte application: faites-moi exécuter, mais auparavant je ferai un dernier voeu que Vous exaucerez.

-Je vois, dit le roi avec regret, que tu es un fidèle sujet, mais la loi est la loi, en effet; tu seras mis à mort mais, d'abord, dis-moi quel est ton voeu.

- Je souhaite donner un grand coup de maillet sur Votre auguste tête.

On crut avoir mal compris, on le fit répéter; il répéta qu'il ne voulait que cela: obéir entièrement à la loi. Grand fut l'embarras du roi et du Conseil. Pour se donner le temps de réfléchir, on le mit en prison. On consulta des juristes, des prêtres et des astrologues; leurs avis concordèrent: le souverain, ultime gardien du droit, ne pouvait se déjuger parce que ses propres intérêts étaient en jeu.

Le défilé des parents et des proches recommença, mais cette fois du palais à la prison. Rien ne semblait arriver à fléchir la tranquille assurance du foulon. En exigeant l'exaucement de son voeu, expliquait-il patiemment, il contribuait au respect de la loi.

C'est seulement la veille du jour fixé pour son exécution qu'il consentit à suggérer une solution à la reine, accourue en personne: puisque sa vie et celle du roi se trouvaient malencontreusement liées par la loi, on ne pouvait les sauver toutes les deux qu'en abolissant une loi si funeste.

Ce que le roi, on s'en doute, fit avec enthousiasme. De soulagement, on chanta, on dansa au palais et dans tout le pays; on félicita, on remercia le roi, avec quelque malice il est vrai.

Pour marquer ce jour mémorable, où il évita une mort certaine, et par reconnaissance, le roi décida en outre que, plus jamais, personne ne se prosternerait devant quiconque en son royaume. En quoi nous sommes, me semble-t-il, le peuple le plus original de la terre. 